\title{
False Beliefs and Misleading Evidence
}

Marc-Kevin Daoust, Harvard University. mk.daoust@live.ca

Forthcoming in Theoria. DOI: $10.1111 /$ theo.12288

Abstract: False beliefs and misleading evidence have striking similarities. In many regards, they are both epistemically bad or undesirable. Yet, some epistemologists think that, while one's evidence is normative (i.e., one's available evidence affects the doxastic states one is epistemically permitted or required to have), one's false beliefs cannot be evidence and cannot be normative. They have offered various motivations for treating false beliefs differently from true misleading beliefs, and holding that only the latter may be evidence. I argue that this is puzzling: If misleading evidence and false beliefs share so many important similarities, why treat them differently? I also argue that, given the striking similarities between false beliefs and misleading evidence, many arguments for the factivity of evidence overgeneralize. That is, if these arguments were conclusive, they would also entail that the evidence cannot be misleading. But this is an overgeneralization, since the evidence can be misleading.

Keywords: evidence, epistemic reasons, epistemic normativity, internalism, externalism, misleading evidence

Suppose you believe (or you are highly confident) that Boris is British for the sole putative reason that he was born in London. The fact that someone was born is London makes it very likely that he or she is British. However, this reason could be misleading: Perhaps Boris was born in London, but he is not British. Or perhaps this proposition is false. That is, perhaps Boris was not even born in London. If you came to learn that "Boris was born in London" is a misleading fact or a false proposition, the support for your belief that Boris is British would be defeated. Believing in accordance with false propositions or misleading facts does not get us closer to the truth.

Misleading facts and false propositions or beliefs have striking similarities. Essentially, they are obstacles to epistemic success. That is, responsiveness to misleading facts or false beliefs are obstacles to finding the truth. As thinkers who want to get closer to the truth, we find them epistemically undesirable.

If we take the striking similarities between misleading facts and false propositions seriously, we are faced with a puzzle. Many epistemologists think that one's evidence is 
normative, in the sense that one's available evidence affects which doxastic states one is epistemically permitted or required to have. ${ }^{1}$ Since there are misleading facts, there is misleading evidence. So, they also think that the misleading facts that are part of one's evidence are normative. However, these epistemologists also think that false beliefs cannot be part of an agent's evidence and cannot be normative (Williamson 2000; Littlejohn 2012; Kiesewetter 2017; Lord 2018). These epistemologists have offered various motivations for treating false beliefs differently from true misleading beliefs, and holding that only the latter may be evidence. In this paper, I argue that these motivations overgeneralize, and also recommend denying that misleading true beliefs can be evidence. But this is an overgeneralization, since the evidence can be misleading.

Section 1 presents this problem more fully. Sections 2 to 4 discuss six popular arguments for the factivity of evidence that rely (implicitly or explicitly) on the epistemic undesirability of false beliefs. If we take the striking similarities between misleading facts and false beliefs seriously, we see that these arguments overgeneralize: They entail not only that false propositions cannot be evidence, but that the evidence cannot be misleading. But this is problematic, since the evidence can be misleading. Agents can know some facts that point in the wrong direction. Section 5 analyzes the plausibility of views according to which one's evidence is normative but one's false beliefs cannot be normative.

\section{The Argument}

\subsection{The Similarities Between False Beliefs and Misleading Evidence}

Consider the following cases:

Bad Case. Unbeknownst to Debby, she is under the influence of a powerful hallucinogen. The drug is very powerful and the illusions are perfect. It seems to her that it is raining

1 The type of ought under discussion is left open. The deliberative ought has to do with "reasons that matter in first-personal deliberation" (Kiesewetter 2017, 13). By way of contrast, the ought of advice has to do with reasons that matter if I were to receive advices from a well-informed third party. See Wedgwood $(2015 ; 2017,89-94)$ on the various types of ought. These types of ought are not necessarily incompatible with each other. Some authors are interested with the natural process by which agents come to acquire knowledge, while others are concerned with how agents should deliberate. This gives rise to various understandings of "ought" that are perfectly legitimate depending on the kind of problem we are interested with. See Littlejohn (2012), Sylvan (m.s.) or Worsnip (2016), for example. 
outside (but this is an illusion). Accordingly, she has a high degree of confidence in the proposition "the sidewalks are slippery tonight," or she believes this proposition.

Good Case. Becky is Debby's internal duplicate. However, she is not deceived. She knows that it is raining outside. Accordingly, she has a high degree of confidence in the proposition "the sidewalks are slippery tonight," or she believes this proposition. ${ }^{2}$

In the Bad Case Debby is hallucinating. It is not a fact that it is raining outside. Since she is responsive to illusions and mere appearances, she is drawn away from the truth, and her beliefs are false. In the remainder of this paper, when I refer to false beliefs, I am interested in the kind of beliefs agents like Debby have. That is, I will be interested in false beliefs that are sensitive to phenomenal experiences, seemings, or appearances in bad cases.

In the Good Case, things are different. Becky has evidence supporting the conclusion that the sidewalks are slippery. The fact that it is raining makes it very likely that the sidewalks are slippery. However, they could be safe. Perhaps unbeknownst to Becky, the city has placed anti-slid strips on sidewalks. In this case, the fact that it is raining is pointing in the wrong direction. It will draw an evidence-responsive agent away from the truth. We can say that, in such cases, the evidence is misleading. Cases of misleading evidence can take different forms. Think of true but improbable events (it is a fact that I am unlikely to win the lottery, but as it happens I will win), cases of misleading testimony from reliable sources (it is a fact that the testifier is unlikely to be wrong, but as it happens he or she is wrong), and so forth. In these situations, some facts are pointing in the wrong direction, and so are misleading.

Some philosophers think that, while the evidence can be misleading, sufficient or decisive evidence for believing P cannot be misleading (Littlejohn 2012, chap. 4). Perhaps the fact that it is raining tonight is insufficient or indecisive evidence, and Becky should not believe, on such a ground, that the sidewalks are slippery outside.

However, recall that belief is not the only doxastic state agents can have. In addition to having beliefs that can be true or false, agents have credences, or degrees of belief, that

2 This case is inspired by Kiesewetter $(2017,162)$. 
can be accurate or inaccurate. ${ }^{3}$ When agents acquire evidence supporting the conclusion that $\mathrm{P}$, they can form the belief that $\mathrm{P}$, but they can also merely raise their degree of confidence in P. Perhaps misleading evidence to believe $\mathrm{P}$ cannot be decisive evidence to believe P. But surely, misleading evidence can raise an agent's degree of confidence in a false proposition.

Suppose Becky's evidence does not warrant believing the proposition "the sidewalks are slippery tonight." However, this information can raise her degree of confidence in this proposition. After all, the fact that it is raining outside makes it more likely that the sidewalks are slippery. However, raising her degree of confidence in this proposition can increase her degree of inaccuracy. That is, she can have a higher degree of belief in a false proposition, or a lower degree of confidence in a true proposition. Again, responsiveness to misleading facts draws agents away from the truth. The evidence can be misleading.

False beliefs and misleading evidence share many similarities. In many regards, they are both epistemically undesirable. They are obstacles to responsible inquiry, they undermine successful deliberation, they compromise reliability, and so forth. Here is a tentative list of similarities between the two:

- Responsible Inquiry and Deliberation. Suppose that, when thinkers deliberate, they should be epistemically responsible. Specifically, in the course of inquiry, they should do their best for searching and finding the truth. ${ }^{4}$ False beliefs and misleading evidence are obstacles to finding the truth. So, responsible thinkers should treat them as undesirable, and ignore them when they recognize them as such. Relatedly, suppose that, when thinkers deliberate, they should care about the truth. Accordingly, they should treat considerations that might deceive them as undesirable, and try to ignore them. False beliefs and misleading evidence deceive agents. So, thinkers should try to ensure that they do not rely on beliefs that are false or evidence that is misleading

3 Agents improve the accuracy of their credences when they raise their degree of confidence in true propositions, or lower their degree of confidence in false propositions.

4 Cloos (2015), Peels and Booth (2014). 
- Defeat. Suppose that, when thinkers deliberate, they should be sensitive to defeaters. ${ }^{5}$ Very roughly, a defeater is a condition in which one's evidence or beliefs do not support believing $\mathrm{P}$ anymore. Among these conditions, coming to know that my evidence for believing $\mathrm{P}$ is misleading, or that my beliefs supporting the conclusion that $\mathrm{P}$ were false, are defeaters for believing P. In the presence of such defeaters, agents do not take their misleading evidence or their false beliefs to support the conclusion that $\mathrm{P}$.

- Reliability: Suppose agents aim at optimizing their ratio of true to false beliefs. ${ }^{6}$ False beliefs and responsiveness to misleading evidence will not improve their ratio of true to false beliefs. Agents who reason from false beliefs or respond to misleading evidence are likely to reach the wrong answer on various issues. So, if agents want to be reliable, they also want to avoid false beliefs and misleading evidence.

- Safety and Knowledge. Suppose agents are permitted to believe P only if they can truly and safely believe P. ${ }^{7}$ Safety entails that, if agents truly believe P, they could not easily have falsely believed P. Responsiveness to false beliefs and misleading evidence undermines the satisfaction of the safety condition. The more agents have false beliefs and misleading evidence supporting $\mathrm{P}$, the easier it is for them to falsely believe P. So, in order to satisfy the safety condition, agents ought to avoid false beliefs and misleading evidence. The same goes for knowledge. Suppose agents ought to believe P only if they are in a position to know that $\mathrm{P}{ }^{8}$ Responsiveness to false beliefs and misleading evidence undermines the knowledge condition. The more agents have false beliefs and misleading evidence, the easier it is for them to falsely believe P (and thus not be in a position to know that $\mathrm{P}$ ).

- Final epistemic value. Suppose that truth (or knowledge) has final epistemic value. ${ }^{9}$ Misleading evidence and false beliefs are not conducive to truth (or knowledge). Responsiveness to misleading evidence and false beliefs brings agents away from the truth (and thus undermine knowledge, for which truth is a necessary condition). In that

5 Schroeder (2011).

6 Goldman (1986).

7 Pritchard $(2007 ; 2008)$.

8 Williamson (2002).

9 Bondy (2015), Goldman (2015), Horwich (2006). 
regard, both misleading evidence and false beliefs are not conducive of final epistemic value.

This is just a sample. The list of epistemic desiderata that false beliefs and misleading evidence both fail to satisfy could go on. I think the point I am making is obvious enough to stop here.

Some of the above desiderata are typical of internalist theories of epistemic norms (like epistemic responsibility, good first-personal deliberation, or sensitivity to defeaters). Others are typical of externalist theories (like reliability, safety, or knowledge). Epistemologists, whether they lean towards internalism or externalism about epistemic norms, think that agents would be better off if they did not respond to their false beliefs and misleading evidence. ${ }^{10}$ Thinkers do not value being wrong or misled: It is something they endure. Epistemically speaking, thinkers would prefer not having false beliefs and ignoring their misleading evidence.

\subsection{The Puzzle: Why Treat False Beliefs Differently from Misleading Evidence?}

Epistemologists have substantive disagreements on the following two questions: First, can some false beliefs be evidence? Second, can some false beliefs be normative (i.e., can some of an agent's false beliefs matter for determining his or her epistemic obligations and permissions)? If we combine the possible answers to these two questions, we get four possible views, as in the following:

10 See, e.g., Simion, Kelp, and Ghijsen (2016). 
Table 1: Views on Putative "False Evidence" and the Normativity of False Beliefs

\begin{tabular}{|c|c|c|}
\hline & $\begin{array}{l}\text { Some false beliefs } \\
\text { are normative }\end{array}$ & $\begin{array}{c}\text { False beliefs } \\
\text { cannot be normative }\end{array}$ \\
\hline $\begin{array}{l}\text { Some false beliefs } \\
\text { are evidence }\end{array}$ & $\begin{array}{c}\text { Normative Falsies: } \\
\text { Comesaña (2018), Fantl and } \\
\text { McGrath (2009), Gibbons } \\
\text { (2013), Conee and Feldman } \\
\text { (2004) } \\
\text { Schroeder (2008)? }\end{array}$ & \\
\hline $\begin{array}{l}\text { False beliefs } \\
\text { cannot be evidence }\end{array}$ & $\begin{array}{l}\text { Normative Truthers: } \\
\text { Sylvan }(2015 ; \text { forthcoming), } \\
\text { Parfit }(2011,34,111)\end{array}$ & $\begin{array}{l}\text { Non-Normative Truthers: } \\
\text { Littlejohn (2012), } \\
\text { Williamson (2002), } \\
\text { Kiesewetter (2017), Lord } \\
\text { (2018) } \\
\text { Mitova (2017)? }\end{array}$ \\
\hline
\end{tabular}

Three out of four possible views are represented in print. According to Normative Truthers, an agent's evidence does not include false beliefs or propositions, but some false beliefs can be normative (qua apparent evidence, for instance). This view is endorsed by Parfit (2011) and Sylvan (2015; forthcoming). For Normative Falsies, an agent's evidence can include false beliefs or propositions, and these falsehoods can be normative. This view is endorsed, among others, by Comesaña (2018), Gibbons (2013), Fantl and McGrath (2009), and Conee and Feldman (2004). Schroeder (2008) might also endorse this view, depending on how to interpret his concept of "subjective evidence." Normative Truthers, an agent's evidence does not include false beliefs or propositions, and

11 There are two ways to interpret Schroeder's view. First, perhaps "subjective" is an adjective qualifying the evidence. So, subjective evidence would be part of one's evidence. But perhaps "subjective" is here meant to distinguish real evidence from subjective evidence. Schroeder would then refer to what Sylvan (2015) and Parfit $(2011,34)$ call "apparent evidence." Sylvan and Parfit think that, while the evidence is factive, apparent evidence can include false propositions. So, there are two different interpretations of Schroeder's view: One entails that there can be false evidence, and the other doesn't. See also Whiting (2018, 2197). 
false beliefs cannot be normative. This view is endorsed by Littlejohn (2012), Williamson (2002), Kiesewetter (2017), and Lord (2018). ${ }^{12}$ Perhaps Mitova (2017) endorses this view. ${ }^{13}$

The divide between Normative Truthers and Normative Falsies is subtle. Both of them think that false beliefs matter for an agent's epistemic permissions and obligations. But for various reasons, Normative Truthers prefer to regiment the concept of evidence so as to only include facts.

For instance, facts can explain why a proposition is true, or why an agent formed or revised his or her doxastic states. Falsehoods lack this explanatory power. ${ }^{14}$ Accordingly, epistemologists might want a concept that has both explanatory power and a role in normative evaluation, and thus reserve the concept of evidence to facts. ${ }^{15}$ Relatedly, sensitivity to facts or the environment is essential to many externalist accounts of justification. ${ }^{16}$ Accordingly, externalists might want a factive concept to express what they have in mind, and, for this purpose, regiment the concept of evidence to facts. There could be other reasons to restrict the concept of evidence to facts. Williamson (2000, chap. 9) suggests that, if we want to know what evidence consists in, we need to consider the contextual function of evidence (in contexts where evidence-responsiveness is important, like science). Littlejohn (2012, sec. 3.3.6) and Mitova (2017, 95) argue that restricting the concept of evidence to facts brings greater conceptual unity between theoretical and practical reason (since practical reasons are typically understood as facts). Sylvan (m.s.) suggests that our concepts should square well with the distinction between justification (and sensitivity to evidence or reasons) and rationality (and sensitivity to apparent evidence or apparent reasons).

12 Although Lord (2018) and Kiesewetter (2017) argue that, in cases where they are deceived, facts concerning an agent's seemings and appearances can be backup evidence. Kiesewetter thinks that, in the absence of defeaters, the fact that it seems to an agent that $\mathrm{P}$ and the fact that $\mathrm{P}$ are equally strong reasons (Kiesewetter 2017, sec. 7.5). Williamson (2000) and Littlejohn (2012, chap. 3) reject this claim.

13 Mitova (2017, chap. 9) argues that evidence is factive and has normative authority. But this is compatible with thinking that some false beliefs also have normative authority.

14 See, e.g., Littlejohn (2012, 103; 2013a) and Lord (2018, 81-6). However, Lord's argument primarily concerns reasons, not evidence.

15 See Fogal (2018, sec. 11.4) for discussion.

16 Schellenberg (2016), for instance, is interested in the kind of evidence that is determined by the environment, and thus is guaranteed to depict it. 
So, for Normative Truthers, we can make a conceptual distinction between evidence and false beliefs (or between evidence and apparent evidence). However, the distinction has limited import for normative issues. We can regiment the concept of evidence so as to only include facts without also saying that false beliefs have no normative status. ${ }^{17}$

The divide between Normative Falsies and Non-Normative Truthers is deeper. Many Non-Normative Truthers think that an agent's available evidence affects which doxastic states he or she is epistemically permitted or required to have. For instance, Littlejohn argues that one's evidence consists in the true propositions one justifiably believes (2012, chap. 4), and that justification is tied to epistemic permissibility $(2012,4){ }^{18}$ Lord and Kiesewetter argue that evidence is factive, and that what agents are epistemically permitted and required to believe is solely determined by their possessed or available evidence (Lord 2014, 155; Lord 2018, secs. 8.3-8.4; Kiesewetter 2017, chaps. 7-8). Williamson says that an agent's evidence consists in the propositions he or she is in a position to know (2000, chap. 9). For Williamson, knowledge matters for determining what agents are epistemically permitted to believe, or the degrees of belief they are epistemically permitted to have (2000, sec. 1.5 ; forthcoming b). ${ }^{19}$

However, Non-Normative Truthers deny that agents are permitted or required to proportion their beliefs and credences to some of their false beliefs. For instance, Kiesewetter rejects Parfit's claim that an agent's false, apparent evidence is normative (2017, sec. 5.6). Littlejohn says that justification is tied to permissibility $(2012,4)$, and that there are no justified false beliefs (2012, sec. 4.2). Williamson thinks that, if one is epistemically permitted to believe $\mathrm{P}$, then one is in a position to know that $\mathrm{P}$, which excludes false beliefs or propositions $(2000,47) .^{20}$

17 But see Gerken (2018) for a worry-namely, that some of the motivations underlying epistemic externalism are compatible with the denial of the factivity of evidence.

18 Littlejohn (2013b, 310) now ties epistemic permissibility to knowledge.

19 On epistemic permissibility and degrees of belief, Williamson says that an agent's evidence consists in his or her knowledge. He endorses the Principal Principle, which roughly says that agents are required to proportion their credences to their knowledge of the objective probabilities. So, in a standard lottery case, Becky's credences are constrained by her knowledge of her ticket's chance of winning. If Becky bought the winning ticket, but had a low chance of winning, her credences will be constrained by misleading evidence. See Williamson (forthcoming b).

20 See also Williamson (forthcoming a, esp. note 18) for a clarification of his earlier views concerning the connection between epistemic permissibility and knowledge. 
Here is the problem. False beliefs and misleading evidence are similar in many regards. Essentially, they are both epistemically undesirable. Accordingly, why think that that misleading facts can be normative evidence but that false beliefs cannot? The puzzle is to explain this distinction, even if it is hard to find a relevant difference between misleading evidence and false beliefs. This is a problem for Non-Normative Truthers, since, as we just saw, many of them think that an agent's evidence (including misleading evidence) ${ }^{21}$ is normative but false beliefs cannot be normative. By contrast, Normative Truthers and Normative Falsies do not commit to this asymmetry. They accept that both false beliefs and misleading evidence can be normative.

More precisely, the puzzle for Non-Normative Truthers is that the following theses are in tension:

1. Evidence is normative (i.e., an agent's available evidence affects what he or she is epistemically permitted or required to believe);

2. Misleading evidence and false beliefs have many striking similarities;

3. False beliefs are not part of an agent's evidence and they are not normative.

Non-Normative Truthers endorse 1 and 3. However, these claims are in tension with 2. If we take the similarities between misleading evidence and false beliefs seriously, we should reject the normative authority of evidence, or accept that some false beliefs can be normative.

The problem is especially clear when taking a closer look at existing arguments against the claim that false beliefs can be evidence. Many of these arguments stress (implicitly or explicitly) the epistemic undesirability of false beliefs. They conclude, from this observation, that false beliefs cannot be part of an agent's evidence. Given the similarities between false beliefs and misleading evidence, these arguments are likely to overgeneralize, and lead to the conclusion that no evidence can be misleading. But the evidence can be misleading. So, the problem is this: Either these arguments are

21 See, e.g., Kiesewetter $(2017,162,167)$ and Lord $(2018,53,218)$. Kiesewetter's "Backup View" (2017, sect. 7.5) also strongly suggests that misleading evidence can be a source of normative reasons. See also note 19. 
inconclusive, or they entail the problematic conclusion that no evidence can be misleading. $^{22}$

In the next sections, I examine six arguments for the factivity of evidence and argue that they overgeneralize in a problematic way.

\section{Williamson's Arguments for the Factivity of Evidence}

\subsection{The Argument From Epistemic Success}

Williamson (2011) argues that the factivity of evidence is a natural consequence of the explanatory priority of success in epistemic evaluation. His argument roughly goes as follows:

(P1) Epistemic norms should give explanatory priority to conditions of epistemic success.

(P2) We can evaluate an agent's epistemic status "from the standpoint of an external observer, with access to information unavailable to the agent" (Williamson 2011, 211).

(P3) From the standpoint of an external observer, it is more epistemically successful to respond to factive evidence than to respond to false beliefs.

(C) So, evidence is factive.

A similar point can be found in Williamson's earlier work. In Knowledge and Its

Limits he argues that, once we assume that evidence is factive, responsiveness to the evidence has an obvious advantage (that responsiveness to false beliefs lack). He says: ${ }^{23}$

Once it is granted that all propositional evidence is true-and therefore... that all evidence consists of true propositions - adjusting our beliefs to the evidence has an obvious point. It is a way of adjusting them to the truth. Although true evidence can still support false conclusions, it will tend to support truths. (Williamson 2000, 202)

22 Again, as discussed in section 1.1, perhaps no sufficient or conclusive evidence to believe P can be misleading (Littlejohn 2012, chap. 4). However, this is compatible with thinking that the evidence can be misleading. Consider the following example. Suppose P is extremely improbable on my evidence (say, I know that P's objective probability is very low). However, as it happens, $\mathrm{P}$ is true. Accordingly, an agent who proportions his or her credences to the evidence will end up with highly inaccurate credences. Even if we deny that sufficient or conclusive evidence for believing P can be misleading, there can still be misleading evidence for other doxastic states, such as credences (provided, for instance, that one's credences are constrained by one's knowledge of the objective probabilities - see note 19).

23 See also Neta $(2018,42-47)$ on the factivity of evidence and truth-conduciveness. 
As we can see, both arguments rely on the importance of success-namely, getting closer to the truth, or being more likely to reach the truth.

The claims made in P1 and P2 contrast with internalist accounts of epistemic norms. Most internalist accounts of epistemic norms have two starting points. First, epistemic norms should be operational from a first-personal point of view. That is, if an agent cannot identify a decidable and effective way to satisfy a given epistemic norm, then he or she does not fall under an obligation to satisfy it. Second, evidence has no essential connection to the truth, or other conditions of epistemic success. Knowledge-first epistemology rejects these starting points. As we can see with Williamson's argument, rejecting these assumptions paves the way for a vindication of the factivity of evidence.

Suppose that P1 and P2 were correct. Then, my contention is this: If we give explanatory priority to epistemic success and evaluate an agent's epistemic status from a third-personal point of view, then we could have an even more restrictive concept of evidence. That is, P1 and P2 provide support against the claim that one's misleading knowledge can be part of one's evidence.

Surely, agents who form and revise their doxastic states in accordance with their knowledge will be somewhat successful. But they would be even more successful if they formed and revised their doxastic states in accordance with their non-misleading knowledge. So, perhaps one's evidence should be his or her non-misleading knowledge. After all, agents who are responsive to their non-misleading knowledge are in a better position to acquire more knowledge and improve the accuracy of their doxastic states, and thus be successful. And as Williamson says, we can conduct epistemic evaluation "from the standpoint of an external observer, with access to information unavailable to the agent" (Williamson 2011,211). If that is correct, then we can have a more restrictive account of evidence. $^{24}$

In other words, if Williamson's argument from success is correct, then it seems that we could argue against misleading evidence on similar grounds, as in the following:

24 Mitova (2017, chap. 9) makes similar observations. She thinks that the most popular justifications of the normative authority of evidence stem from the epistemic value of true belief. See also Alvarez (2018, 163 ) on the favouring relation and good-making features. 
(P1) Epistemic norms should give explanatory priority to conditions of epistemic success.

(P2) We can evaluate an agent's epistemic status "from the standpoint of an external observer, with access to information unavailable to the agent" (Williamson 2011, 211).

(P3)* From the standpoint of an external observer, it is more epistemically successful to respond to non-misleading evidence than to respond to misleading evidence.

(C)* So, one's evidence cannot be misleading.

The problem is that the evidence can be misleading. (C)* is false. So, Williamson's argument from success overgeneralizes: If we accept (P1) and (P2), we are led to an implausible conclusion.

\subsection{The Arguments from the Functions of Evidence}

For Williamson, we can determine the properties of evidence by analyzing the functional role of evidence in some contexts, like scientific inquiry. As he says, "any restriction on what counts as evidence should be well-motivated by the function of evidence" (Williamson 2000, 203, emphasis added). Williamson does not tell us exactly why we should be functionalist concerning the nature of evidence. Yet, a functionalist framework makes sense here: If we want to know what is a kidney, we can look at the function played by kidneys for an organism. Similarly, if we want to know the nature of evidence, we can look at the function(s) played by evidence for thinkers who deliberate about what to believe, or for scientists who are trying to figure out which theory is correct, and so forth.

However, functionalist frameworks are compatible with different ways of analyzing defective tokens. Suppose Jim has an accident and his kidneys are badly injured. They do not filter blood anymore and they cannot heal. A kidney's function is, among other things, to filter blood. Should we say that (i) Jim lost his kidneys or that (ii) Jim now has bad kidneys? Functional analyses are compatible with both conclusions.

Those who are inclined to say that Jim has bad kidneys roughly think that, regardless of whether they are defective or not, Jim's organs are supposed to filter blood. They are simply bad at doing it. Accordingly, Jim has bad kidneys. Those who are inclined to say that Jim lost his kidneys think that his organs do not meet the bare minimum for 
counting as kidneys. This is the threshold commitment, as described by Lindeman: "For norm-governed kinds, an individual must at least partially satisfy the constitutive norms of a kind, or partially meet the constitutive aim of a kind, in order to be a member of that kind" (Lindeman 2017, 235-36). These two distinct interpretations are compatible with the functionalist analysis of kidneys. ${ }^{25}$

Similarly, suppose that evidence has functions F, where $\mathrm{F}$ can include guiding agents to the truth or knowledge, confirming hypotheses, and so forth. And suppose Jim's beliefs do not play the functional roles described in F. Say, his beliefs are false or misleading. Misleading facts and false beliefs are bad guides to the truth. So, we could classify both of them as bad evidence. But we could also say that misleading facts and false beliefs cannot be evidence, because they do not even partially meet the constitutive aim of evidence (like drawing agents closer to the truth). So, should we say that (i) Jim's beliefs are bad evidence, or that (ii) Jim's beliefs are not part of his evidence?

As with the injured kidney example, those who are inclined to say that Jim has bad evidence roughly think that, regardless of whether they are defective or not, his beliefs have functions F. They are supposed to have features F. But as it happens, his beliefs are bad at fulfilling these functions. Those who are inclined to say that Jim lacks evidence think that his beliefs do not meet some sort of bare functional minimum. A minimal threshold (in terms of truth-conduciveness, confirmation, etc.) is not met by such beliefs. Both interpretations are compatible with the functionalist analysis of evidence.

With these remarks in mind, we can take a closer look at Williamson's functionalist arguments. His first argument stems from the function of evidence for confirming hypotheses. He writes:

When we prefer an hypothesis $\mathrm{h}$ to an hypothesis $\mathrm{h} *$ because $\mathrm{h}$ explains our evidence e better than $\mathrm{h} *$ does, we are standardly assuming e to be known; if we do not know e, why should h's capacity to explain e confirm $h$ for us? (Williamson 2000, 200)

25 See Lindeman (2017) for discussion on both interpretations. See also Ehrenberg (2016, chap. 2) on a distinction between membership and success (e.g., there could be necessary conditions for being a kidney, and additional conditions for being a good kidney). 
At first sight, the argument has traction. If one's evidence were false, one would have no clear reason to prefer the hypothesis that better explain one's evidence.

However, when we prefer an hypothesis $\mathrm{h}$ to an hypothesis $\mathrm{h}$ (because $\mathrm{h}$ explains our evidence better), we also typically assume that our evidence is not misleading. Yet this does not lead us (and Williamson) to conclude that the evidence cannot be misleading.

Here is another way to put it. Williamson's first functionalist argument for the factivity of evidence goes as follows:

(P1) Suppose we prefer an hypothesis $\mathrm{h}$ to an hypothesis $\mathrm{h}^{*}$ because $\mathrm{h}$ explains our evidence e better than $\mathrm{h}^{*}$ does.

(P2) Assuming we did not know e, we would doubt that h's capacity to explain e confirm $\mathrm{h}$ for us.

(C) So, given P1 and P2, e is known (and factive).

However, this argument is structurally similar to the following:

(P1) Suppose we prefer an hypothesis $h$ to an hypothesis $h^{*}$ because $h$ explains our evidence e better than $\mathrm{h}^{*}$ does.

(P2)* Assuming e were misleading, we would doubt that h's capacity to explain e confirm $\mathrm{h}$ for us.

(C)* So, given P1 and P2*, e is not misleading.

Those who accept P2 should also accept P2*. Just as we should doubt that P explains $\mathrm{H}$ in cases where $\mathrm{P}$ is a false proposition, we should doubt that $\mathrm{P}$ explains $\mathrm{H}$ in cases where $\mathrm{P}$ is a misleading fact. But clearly, $(\mathrm{C})^{*}$ is mistaken. There can be misleading evidence. So, Williamson's argument overgeneralizes.

Williamson's second functionalist argument stems from the relationship between truth and evidence. He writes:

If one's evidence included falsehoods, it would rule out some truths, by being inconsistent with them. One's evidence may make some truths improbable, but it should not exclude any outright. (Williamson 2000, 201) 
Williamson is here introducing a restriction on the concept of evidence: He says that the evidence should not exclude truths outright. But recall that, for Williamson, restrictions on the concept of evidence should come from its function. Responsiveness to the evidence is supposed to bring agents closer to the truth or knowledge. This is one of the functions of evidence: Just as (good) kidneys filter blood, (good) evidence gets us closer to the truth or knowledge.

As I said earlier, those who accept the functionalist analysis of evidence should think that there is something wrong with putative false evidence. In accordance with Williamson's remarks, false beliefs are clearly defective: They do not bring agents closer to the truth, and they are inconsistent with some truths. But does this entail that evidence cannot be false? Not necessarily. Functionalists could think that, since false propositions are inconsistent with some truths, false beliefs are bad or undesirable evidence (a conclusion that many philosophers would agree with). One can embrace functionalism about evidence and think that false beliefs can be part of one's evidence.

Williamson could object, in accordance with the threshold commitment, that false beliefs do not meet the bare functional minimum to count as evidence. If that is correct, then false beliefs cannot be evidence. However, misleading facts also draw agents away from the truth. They can make some truths extremely improbable. So, one could also argue, on the same ground, that misleading facts or beliefs do not meet the bare functional minimum to count as evidence. But this would be an overgeneralization. The evidence can be misleading. Agents can be in a position to know some propositions that will draw them away from the truth.

Perhaps Williamson thinks that misleading evidence is bad evidence, while false beliefs cannot be evidence. But from a functionalist point of view, there is no reason why we should classify misleading facts differently from false beliefs. If we think that the function of evidence is to get us closer to the truth or knowledge, misleading beliefs and false beliefs are both defective for the same reasons. So, if restrictions on the concept of evidence come from its function, there is no reason why, on the one hand, one's evidence may make some truths extremely improbable, but on the other hand, it should not exclude 
them. In both cases, the evidence does not play its functional role of getting agents closer to the truth.

Williamson could then respond that misleading facts meet the bare functional minimum because they are facts, and only facts can stand in explanatory relations between true propositions or events. Accordingly, misleading facts can stand in explanatory relations, but falsehoods cannot. My response to this objection goes as follows: If the evidence for believing $\mathrm{P}$ is misleading, there is no explanatory relation between the evidence and $\mathrm{P}$. That is, when the evidence for believing $\mathrm{P}$ is misleading, $\mathrm{P}$ is false, and so there cannot be an explanatory relation between the evidence and what it supports. If explanatory relations were part of the function of evidence and constrained its nature, this would strongly suggest that the evidence cannot be misleading. But again, this would be an overgeneralization: The evidence can be misleading. ${ }^{26}$

\section{Littlejohn's Linguistic Observations}

According to Littlejohn (2012, sec. 3.3.5), some linguistic observations suggest that evidence is factive. To see why, consider the following assertions:

(1) "I believe Q for the reason that P, but I don't know that P."

(2) "I believe I should believe Q for the reason that P, but I don't know that P."

For Littlejohn, these assertions sound contradictory. If such assertions are incoherent, there must be a problem with claiming that one's evidence cannot be known. This "linguistic evidence" suggests that epistemic reasons, like one's evidence, are known. Since knowledge is factive, then so too is one's evidence (Littlejohn 2012, 102-3).

26 A variant of this objection goes as follows: Only facts can explain why an agent is permitted to have doxastic attitude D towards P. My response to this variant of the objection roughly goes as follows: Of course, there must be some facts explaining why agents are epistemically permitted to form or revise some of their beliefs. But there are facts concerning one's false beliefs, and these facts can explain why agents are permitted to have doxastic attitude $\mathrm{D}$ towards $\mathrm{P}$. If $\mathrm{A}$ falsely believes that $\mathrm{P}$, it is a fact that $\mathrm{A}$ falsely believes that $\mathrm{P}$, and this fact can explain (in part) why $\mathrm{A}$ is permitted to believe what is entailed by P. The "factivity" at stake in this variant of the objection does not preclude that false beliefs matter for determining one's epistemic permissions and obligations. I thank a referee for inviting me to discuss these objections on behalf of Williamson. 
The problem is that, if (1) or (2) are incoherent, then the following assertions are also incoherent:

(3) "I believe Q for the reason that P, but P is misleading evidence for believing Q."

(4) "I believe I should believe Q for the reason that P, but P is misleading evidence for believing Q."

If agents who assert (1) or (2) are incoherent, then agents who asserts (3) or (4) also display some kind of incoherence. ${ }^{27}$ If $\mathrm{P}$ is misleading evidence for believing $\mathrm{Q}$, then believing $\mathrm{Q}$ for the reason that $\mathrm{P}$ does not make sense. So, if we take the linguistic evidence in (1) and (2) to suggest that evidence is known, we should also take the linguistic evidence in (3) and (4) to suggest that the evidence cannot be misleading. Again, the problem is that the evidence can be misleading. So, these linguistic observations overgeneralize.

Littlejohn discusses other linguistic practices which suggest that evidence is factive. Consider the following case (Littlejohn 2012, 104):

$H A R R Y$ : Do they have solid evidence against Leo?

GORDON: They think they do. Here's the evidence they have: that he was the last one to see the victim alive, that he lied about his whereabouts on the night of the crime, that his fingerprints were on the murder weapon, and that he wrote a letter containing details the police think only the killer could have known.

$H A R R Y$ : But didn't you say that he wasn't the last person to see him alive and his fingerprints couldn't have been on the weapon?

GORDON: That's right. He also didn't lie about his whereabouts and wasn't the last one to see him alive.

Littlejohn takes Gordon's admission that the putative evidence is false to be puzzling. It seems that, if the propositions asserted by Gordon are false, they cannot be part of the solid evidence against Leo. So, these linguistic observations suggest that evidence is factive.

Suppose, as Littlejohn suggests, that Gordon and Leo's linguistic practices lent support to the claim that evidence is factive. Once again, the problem is that this kind of linguistic

27 See also Chevarie-Cossette (2019) on a similar problem. 
evidence would overgeneralize. There is also something odd with the following conversation:

$H A R R Y$ : Does the prosecution have solid evidence against Leo?

GORDON: They think they do. Here's the evidence they have: that he was the last one to see the victim alive, that he lied about his whereabouts on the night of the crime, and that his fingerprints were on the murder weapon, and that he wrote a letter containing details the police think only the killer could have known.

$H A R R Y$ (revised): But didn't you say that all of these facts are misleading, and that we can prove Leo's innocence?

GORDON (revised): That's right. All the facts available to the prosecution are misleading. We can easily prove Leo's innocence, and that the evidence for his guilt is misleading. But the prosecution still has solid evidence against Leo.

What is puzzling in the above conversation is that, if the prosecution has solid evidence against Leo, Gordon should not be in a position to easily prove that Leo is innocent. There is something puzzling with claiming, on the one hand, that there is solid evidence against Leo, and claiming, on the other hand, that this evidence is misleading.

So, there is something odd with these assertions. However, no one would conclude from this observation that the evidence cannot be misleading. Some facts do point in the wrong direction, and responsiveness to these facts draws agents away from the truth. So, these linguistic observations overgeneralize. They are not good indicators of the nature of evidence.

\section{Mitova's Arguments for the Factivity of Evidence}

\subsection{A Note on Mitova's Argument}

In Believable Evidence (2017), Mitova argues that evidence consists of veridical psychological states. Her view offers a compromise between propositional factualism (like Williamson (2000), who thinks that an agent's evidence consists of his or her knowledge) and psychologism (like Conee and Feldman (2004), who think that an agent's evidence 
consists of his or her mental states). Her argument for the factivity of evidence is presented in chapter 4. It goes as follows:

(P1) Normative reasons for belief are psychological states.

(P2) Content-related normative reasons for believing P speak in favour of the truth of $\mathrm{P}$.

(P3) Non-veridical psychological states don't genuinely speak in favour of the truth of a proposition.

(C1) So, only veridical psychological states can be content-related normative reasons for belief.

(P4) The evidence for $\mathrm{P}$ is a content-related normative reason to believe that $\mathrm{P}{ }^{28}$

(C) So, only veridical psychological states can be evidence. ${ }^{29}$

The key step in her argument for denying that false propositions can be evidence is P3. So, we will analyze the arguments favouring P3. In the remainder of this section, I discuss two arguments Mitova gives for P3. I argue, once again, that these considerations overgeneralize to misleading evidence.

\subsection{Falsehoods and Speaking in Favour of the Truth of A Proposition}

Mitova's first argument for P3 is that it seems to be a platitude. There is a sense in which a perceptual illusion or a false belief cannot "really speak in favour of the truth of anything"

(Mitova 2017, 94). In order to stress this point, she then offers the following case:

False Belief: "Suppose I truly believe that either you or Baingana left chocolates on my doorstep during the night, and that I falsely believe that Baingana did. Clearly, my false belief that he did cannot speak in favour of the

28 Those who are familiar with Mitova's views might find P4 puzzling. In chapter 7 of Believable Evidence, when discussing the case of an agent who possesses misleading evidence, she writes that "[the agent's belief] is not based on good reasons; it is, instead, based on misleading evidence" (Mitova 2017, 181). On page 182, she says that "misleading evidence... is in the ballpark of good reasons-it is evidence manqué...." This seems to contradict the claim that the evidence for believing $\mathrm{P}$ is a normative reason to believe P. So, why not replace P4 with something like: "The non-misleading evidence for a proposition is a good reason to believe that proposition"?

I will not take a stance on this issue. But note that, if only the non-misleading evidence to believe $\mathrm{P}$ is a good reason to believe $P$, then the argument of chapter 4 should be reformulated as follows:

(P1) Normative reasons for belief are psychological states.

(P2) Content-related normative reasons for believing $\mathrm{P}$ speak in favour of the truth of $\mathrm{P}$.

(P3) Non-veridical psychological states don't genuinely speak in favour of the truth of a proposition.

(C1) So, only veridical psychological states can be content-related normative reasons for belief.

(P4)* The non-misleading evidence for $\mathrm{P}$ is a content-related normative reason to believe that $\mathrm{P}$.

(C)* So, only veridical psychological states can be non-misleading evidence.

This revised argument does not support the conclusion that evidence is factive-it merely supports the conclusion that non-misleading evidence is factive. I here ignore this complication, since I wish to engage with a version of her argument that entails the factivity of evidence tout court.

29 Mitova (2017, chap. 4). 
truth of the proposition 'You didn't leave chocolates on my doorstep'. If the belief is false, then Baingana didn't leave the chocolates." (Mitova 2017, 94)

There is a sense in which false beliefs do not speak in favour of the truth of a proposition: An observer with all the relevant information regarding $\mathrm{P}$ would not think that one's false beliefs support the conclusion that P. However, the same could be said of misleading evidence: An observer with all the relevant information regarding $\mathrm{P}$ would not think that one's misleading evidence for believing $\mathrm{P}$ supports the conclusion that $\mathrm{P}$. For instance, if the observer knows that the evidence for believing $\mathrm{P}$ is misleading, he or she would not become more confident, on the evidence, that $\mathrm{P}$.

Consider the following case. It is identical to False Belief, with the exception that the belief is misleading instead of false:

Misleading Belief: I truly believe that either you or Baingana left chocolates on my doorstep last night. However, I believe that there is a $99.9 \%$ chance that Baingana did (Or perhaps I believe that Baingana is the only person who regularly left chocolates on my doorstep for the past several years). But the proposition I believe is misleading, since Baingana did not leave the chocolates on my doorstep last night. As with false beliefs, there is a sense in which the misleading proposition I believe does not speak in favour of the truth of the proposition 'You didn't leave chocolates on my doorstep'. If the believed proposition is misleading (i.e., if the content of my belief points in the wrong direction), then Baingana didn't leave the chocolates.

In False Belief, Mitova's intuition seems to be motivated by the fact that, if my belief is false, then Baingana did not leave the chocolates. However, if the content of my belief is misleading, then Baingana did not leave the chocolates. Her case against false evidence generalizes against misleading evidence. So, her argument overgeneralizes.

\subsection{The Argument From the Phenomenology of Deliberation}

Mitova's second argument against false evidence comes from the phenomenology of deliberation. She writes:

[The impossibility of false evidence] is faithful to the phenomenology of deliberation. When I take a consideration to favour an action or a belief, I take that consideration to obtain. The moment it is shown to me that it doesn't, I stop thinking that it favours the action or belief.... So, the phenomenology of 
reflecting on our reasons supports the thesis that false beliefs don't genuinely favour action or belief. (Mitova 2017, 95)

For Mitova, when agents take some proposition to favour or support a conclusion, they take this consideration to be a fact (or a true proposition). If they learn that the proposition is false, they immediately stop thinking that the proposition supports a conclusion. According to her, the best explanation of this observation concerning the phenomenology of deliberation is that evidence cannot be false. In view of the foregoing, she concludes that evidence cannot be false.

However, there is also a sense in which misleading facts do not square well with the phenomenology of deliberation. Suppose, once again, that I truly believe that either you or Baingana left chocolates on my doorstep last night. I misleadingly believe that there is a 99.9\% chance that Baingana did. Then, I come to learn that you left the chocolates on my doorstep. Since I have this new information, I immediately stop thinking that the fact that there was a $99.9 \%$ chance that Baingana left the chocolates favours the conclusion that Baingana did it. That is, upon learning new information, I take my misleading evidence to be defeated. I revise the support relation between the proposition "There was a $99.9 \%$ chance that Baingana left the chocolates" and "Baingana did it."

From a phenomenological point of view, false beliefs and misleading beliefs have striking similarities: Agents take these considerations to be defeated once they realize they are false or misleading. Also, agents take these considerations to be obstacles to successful deliberation. If Mitova's argument from the phenomenology of deliberation were conclusive, we should also conclude that the evidence cannot be misleading. But some facts do point in the wrong direction. The argument overgeneralizes. ${ }^{30}$

\section{Conclusion}

Epistemically speaking, misleading evidence and false beliefs are both undesirable. Responding to misleading evidence, or believing in accordance with what it entailed by our

30 Mitova also offers a third argument for the factivity of evidence. This argument roughly says that a factive account of evidence allows for greater conceptual unity between practical and epistemic reasons. See section 1 and the conclusion for a short discussion of these types of arguments. 
false beliefs, is not truth-conducive. This gives rise to a problem for those who endorse the following three theses:

1. Evidence is normative (i.e., an agent's available evidence affects which doxastic states he or she is epistemically permitted or required to have);

2. Misleading evidence and false beliefs have many striking similarities;

3. False beliefs are not part of an agent's evidence and they are not normative.

Many Non-Normative Truthers endorse 1 and 3. However, false beliefs and misleading have many striking similarities (as stated in 2). Accordingly, it is expected that arguments against putative false evidence, or the normativity of false beliefs, will also generalize to misleading evidence. But this conflicts with either 1 or 3 . So, Non-Normative Truthers find themselves in an uncomfortable position. Why think that misleading evidence is normative, but that false beliefs can't be normative evidence?

Taking a closer look at existing arguments for the factivity of evidence revealed this tension. For Non-Normative Truthers, false beliefs cannot be part of one's evidence. Whether this is made explicit or not, many of their arguments revolve around the epistemic undesirability of false beliefs. However, given the striking similarities between false beliefs and misleading evidence, these arguments overgeneralize. In sections 2 to 4 , we saw that six arguments against putative false evidence overgeneralize.

Of course, as discussed in section 1.2, restricting evidence to facts can be good conceptual engineering. For instance, facts have explanatory power, while falsehoods do not. ${ }^{31}$ If $\mathrm{P}$, then $\sim \mathrm{P}$ can't explain events in the world. Epistemologists might want a concept that has both an explanatory power and a role in normative epistemic evaluation. Then, restricting the concept of evidence to facts could be useful to some epistemologists. This could, for instance, clarify some philosophical problems, or simplify causal theories of knowledge. ${ }^{32}$ But regimenting the concept of evidence so as to only include facts (for the

31 See section 1.2.

32 But note that good conceptual engineering could also support a non-factive concept of evidence. Perhaps not restricting the concept of evidence to facts could clarify some philosophical problems, or simplify some theories of normativity. All I am saying is that it could be the case that regimenting the concept of evidence so as to only include facts is good conceptual engineering. 
sake of clarity, simplicity, and the like) doesn't entail that false beliefs cannot have normative force.

In summary, some Non-Normative Truthers think that evidence is normative (including misleading evidence), and that false beliefs are not. However, the kind of arguments they give against the normativity of false beliefs overgeneralize against the normativity of misleading evidence. So, they need to find new arguments against the normativity of false beliefs. However, in order to avoid overgeneralization, these arguments must target some specific properties of false beliefs that are not shared with misleading evidence. This will not be an easy task, since, from an epistemic point of view, false beliefs and misleading evidence share many relevant properties. Thus, the striking similarities between false beliefs and misleading evidence give rise to a serious challenge for NonNormative Truthers.

\section{References}

Alvarez, Maria. 2018. "False Beliefs and the Reasons We Don't Have." In The Factive Turn in Epistemology, 161-76. Cambridge: Cambridge University Press.

Bondy, Patrick. 2015. "Epistemic Value.” In Internet Encyclopedia of Philosophy.

Chevarie-Cossette, Simon-Pierre. 2019. "Self-Defeating Beliefs and Misleading Reasons." International Journal of Philosophical Studies 27 (1): 57-72.

Cloos, Christopher Michael. 2015. "Responsibilist Evidentialism.” Philosophical Studies 172 (11): 2999-3016.

Comesaña, Juan. 2018. "A Plea for Falsehoods." Philosophy and Phenomenological Research. https://doi.org/10.1111/phpr.12523.

Conee, Earl, and Richard Feldman. 2004. Evidentialism: Essays in Epistemology. Oxford University Press.

Ehrenberg, Kenneth M. 2016. The Functions of Law. Oxford: Oxford University Press.

Fantl, Jeremy, and Matthew McGrath. 2009. Knowledge in an Uncertain World. Oxford: Oxford University Press.

Fogal, Daniel. 2018. "Deflationary Pluralism about Motivating Reasons." In The Factive Turn in Epistemology, 193-218. Cambridge: Cambridge University Press.

Gerken, Mikkel. 2018. "The New Evil Demon and the Devil in the Details." In The Factive Turn in Epistemology, 102-22. Cambridge: Cambridge University Press.

Gibbons, John. 2013. The Norm of Belief. Oxford: Oxford University Press. 
Goldman, Alvin. 1986. Epistemology and Cognition. Cambridge: Harvard University Press.

—. 2015. "Reliabilism, Veritism, and Epistemic Consequentialism." Episteme 12 (02): 131-143.

Horwich, Paul. 2006. "The Value of Truth.” Noûs 40 (2): 347-360.

Kiesewetter, Benjamin. 2017. The Normativity of Rationality. Oxford: Oxford University Press.

Lindeman, Kathryn. 2017. "Constitutivism without Normative Thresholds.” J. Ethics \& Soc. Phil. 12: 231.

Littlejohn, Clayton. 2012. Justification and the Truth-Connection. Cambridge: Cambridge University Press.

—. 2013a. "No Evidence Is False.” Acta Analytica 28: 145-59.

- 2013b. "The Russellian Retreat." Proceedings of the Aristotelian Society 113: 293-320.

Lord, Errol. 2018. The Importance of Being Rational. Oxford: Oxford University Press.

Mitova, Veli. 2017. Believable Evidence. Cambridge: Cambridge University Press.

Neta, Ram. 2018. "Your Evidence Is the Set of Facts That Are Manifest to You." In The Factive Turn in Epistemology, 32-49. Cambridge: Cambridge University Press.

Parfit, Derek. 2011. On What Matters: Volume One. Oxford University Press.

Peels, Rik, and Anthony Booth. 2014. "Why Responsible Belief Is Permissible Belief." Analytic Philosophy 55 (1): 75-88.

Pritchard, Duncan. 2007. “Anti-Luck Epistemology.” Synthese 158 (3): 277-297.

- 2008. "Sensitivity, Safety, and Anti-Luck Epistemology." The Oxford Handbook of Skepticism, 437-455.

Schellenberg, Susanna. 2016. "Phenomenal Evidence and Factive Evidence." Philosophical Studies 173: 875-96.

Schroeder, Mark. 2008. "Having Reasons.” Philosophical Studies 139 (1): 57-71.

- 2011. "What Does It Take to 'Have' a Reason." In Reasons for Belief, edited by Andrew Reisner and Asbjørn Steglich-Petersen, 201-222. Cambridge: Cambridge University Press.

Simion, Mona, Christoph Kelp, and Harmen Ghijsen. 2016. "Norms of Belief." Philosophical Issues 26 (1): 374-92. https://doi.org/10.1111/phis.12077.

Sylvan, Kurt. m.s. "On Divorcing the Rational and the Justified." Unpublished Manuscript. . forthcoming. "Respect and the Reality of Apparent Reasons." Philosophical Studies. 
- 2015. "What Apparent Reasons Appear to Be." Philosophical Studies 172 (3): 587-606. https://doi.org/10.1007/s11098-014-0320-1.

Wedgwood, Ralph. 2015. "The Pitfalls of 'Reasons."” Philosophical Issues 25 (1): 123143.

- 2017. The Value of Rationality. Oxford: Oxford University Press.

Whiting, Daniel. 2018. "Right in Some Respects: Reasons as Evidence." Philosophical Studies 175 (9): 2191-2208.

Williamson, Timothy. Forthcoming a. "Justification, Excuses and Sceptical Scenarios." In The New Evil Demon, edited by Julien Dutant and Fabian Dorsch. Oxford: Oxford University Press.

- Forthcoming b. "Knowledge, Credence, and the Strength of Belief." In Expansive Epistemology: Norms, Action, and the Social World. Routledge.

- 2002. Knowledge and Its Limits. Oxford University Press.

-. 2011. "Knowledge First Epistemology." In The Routledge Companion to Epistemology, 234-244. Routledge.

Worsnip, Alex. 2016. "Moral Reasons, Epistemic Reasons and Rationality." The Philosophical Quarterly 66 (263): 341-361. 